OPEN ACCESS

Edited by:

Cemil Izgi,

International Hospital-Acibadem Healthcare Group, Turkey

Reviewed by:

Eisuke Amiya,

The University of Tokyo Hospital, Japan

Plinio Cirillo,

University of Naples Federico II, Italy

*Correspondence:

Marion A. Hofmann Bowman mhofmann@medicine. bsd.uchicago.edu

Specialty section:

This article was submitted to General Cardiovascular Medicine,

a section of the journal

Frontiers in Cardiovascular Medicine

Received: 04 January 2017 Accepted: 06 March 2017

Published: 27 March 2017

Citation:

Narang N, Lang RM, Liarski VM, Jeevanandam $V$ and Hofmann Bowman MA (2017) Aortic

Valve Replacement for Moderate Aortic Stenosis with Severe Calcification and Left Ventricualr Dysfunction-A Case Report and Review of the Literature.

Front. Cardiovasc. Med. 4:14. doi: 10.3389/fCvm.2017.00014

\section{Aortic Valve Replacement for Moderate Aortic Stenosis with Severe Calcification and Left Ventricualr Dysfunction-A Case Report and Review of the Literature}

\author{
Nikhil Narang ${ }^{1}$, Roberto M. Lang ${ }^{1}$, Vladimir M. Liarski², Valluvan Jeevanandam ${ }^{3}$ and \\ Marion A. Hofmann Bowman ${ }^{1 *}$ \\ 'Department of Medicine, Section of Cardiology, University of Chicago Medical Center, Chicago, IL, USA, \\ ${ }^{2}$ Department of Medicine, Section of Rheumatology, University of Chicago Medical Center, Chicago, IL, USA, \\ ${ }^{3}$ Department of Surgery, University of Chicago Medical Center, Chicago, IL, USA
}

A 55-year-old man with a history of erosive, seropositive rheumatoid arthritis (RA), and interstitial lung disease presented with shortness of breath. Echocardiography showed new-onset severe left ventricular (LV) dysfunction with an ejection fraction (EF) of $15 \%$ and moderately increased mean aortic valve gradient of $20 \mathrm{mmHg}$ in a trileaflet aortic valve with severe sclero-calcific degeneration. Coronary angiography revealed no significant obstructive coronary disease. Invasive hemodynamic studies and dobutamine stress echocardiography were consistent with moderate aortic stenosis. Guideline directed medical therapy for heart failure with reduced EF was initiated; however, diuretics and neurohormonal blockade (beta-blocker and angiotensin receptor blocker) provided minimal improvement, and the patient remained functionally limited. Of interest, echocardiography performed 1 year prior to his presentation showed normal LV EF and mild aortic leaflet calcification with moderate stenosis, suggesting a rapid progressing of calcific aortic valve disease. Subsequently, the patient underwent surgical aortic valve replacement and demonstrated excellent postsurgical recovery of LV EF (55\%). Calcific aortic valve disease is commonly associated with aging, bicuspid aortic valve, and chronic kidney disease. Pathophysiological mechanism for valvular calcification is incompletely understood but include osteogenic transformation of valvular interstitial cells mediated by local and systemic inflammatory processes. Several rheumatologic diseases including RA are associated with premature atherosclerosis and arterial calcification, and we speculated a similar role of RA accelerating calcific aortic valve disease. We present a case of accelerated aortic valve calcification with (only) moderate stenosis, complicated by a rapid decline in LV systolic performance. Guidelines for AVR in moderate stenosis without concomitant cardiac surgery are not well established, although it should be considered in selected patients.

Keywords: calcific aortic valve disease, aortic stenosis, aortic valve replacement, rheumatoid arthritis, heart failure 


\section{INTRODUCTION}

A 55-year-old man with a medical history significant for erosive, seropositive rheumatoid arthritis (RA), and interstitial lung disease (ILD) was hospitalized for shortness of breath and bilateral foot pain over the past 3 weeks. He described worsening pain in the bilateral medial malleoli and both great toes similar to pain he had in the past related to his diagnosis of RA. He described becoming more dyspneic on exertion than his baseline, for which he required supplemental oxygen. Initial vital signs on presentation were as followed: blood pressure of $146 / 106 \mathrm{mmHg}$, heart rate 124 beats per minute and regular, respiratory rate of 28 breaths per minute, body mass index $34.5 \mathrm{~kg} / \mathrm{m}^{2}$, and pulse oximetry was $92 \%$ on $3 \mathrm{~L}$ supplemental oxygen by nasal cannula. The patient was alert and had mild respiratory distress on presentation. Cardiac examination was notable for a soft systolic murmur on the left sternal border, jugular venous distension to $15 \mathrm{mmHg}$ above the clavicle, and fine inspiratory crackles at the bases of both lungs. Skin was warm to touch with $2+$ lower extremity edema bilaterally from the mid-shin downward. Initial laboratory values were notable for sodium of $133 \mathrm{mmol} / \mathrm{L}$, potassium $4 \mathrm{mmol} / \mathrm{L}$, creatinine $1.3 \mathrm{mg} / \mathrm{dL}$, and an elevated N-terminal pro b-type natriuretic peptide of $1,829 \mathrm{pg} / \mathrm{mL}$ (Table 1). LDL was $119 \mathrm{mg} /$ $\mathrm{dL}$, HDL $56 \mathrm{mg} / \mathrm{dL}$, trigylcerides $166 \mathrm{mg} / \mathrm{dL}$, glucose $91 \mathrm{mg} / \mathrm{dL}$, and HbAlc 5.5\%. White blood cell count and hemoglobin were within normal limits at $6.3 \times 10^{3} / \mu \mathrm{L}$ and $15.7 \mathrm{~g} / \mathrm{dL}$, respectively. The electrocardiogram showed sinus tachycardia, and no ST and T wave changes, concerning for acute ischemia. Prior to admission, medications included albuterol-ipratroprium 18-103 $\mu \mathrm{g} 2$ puffs four times per day, carvedilol $6.25 \mathrm{mg}$ twice a day, famotidine $20 \mathrm{mg}$ twice a day, furosemide $20 \mathrm{mg}$ once daily, certolizumab injection once per month, and hydroxychloroquine $200 \mathrm{mg}$ twice a day.

Chest X-ray revealed moderate cardiomegaly with bibasilar consolidations and moderate pulmonary edema with small pleural effusions bilaterally. Bilateral foot X-rays revealed chronic erosions at the head of the left great toe and mild soft tissue swelling and a chronic appearing erosion of the proximal phalanx of the right great toe, both unchanged from prior study. His foot pain responded to analgesics.

The clinical presentation was suggestive of acute decompensated heart failure. This was confirmed with the transthoracic echocardiogram that demonstrated severely decreased left

\section{TABLE 1 | Serial measurements of pro-BNP.}

\begin{tabular}{ll}
\hline Date & Pro-BNP (reference range \\
& $<125 \mathrm{pg} / \mathrm{mL})$
\end{tabular}

\begin{tabular}{lr}
\hline $03 / 2014$ & 63 \\
$12 / 2014$ & 234 \\
$03 / 2015$ & 548 \\
$04 / 2015$ & 852 \\
$11 / 2015$ & 1,520 \\
$11 / 2015$ & 1,829 \\
$12 / 2015$ & 1,027 \\
$03 / 2016$ & 2,035 \\
$\rightarrow 7 / 2016$ surgical aortic valve replacement & \\
$11 / 2016$ & 239
\end{tabular}

Frontiers in Cardiovascular Medicine | www.frontiersin.org ventricular (LV) function with an ejection fraction (EF) of $10-15 \%$, moderate mitral regurgitation, severe right ventricular dysfunction, and severe tricuspid regurgitation. The severity of AS could not be assessed due to image acquisition quality. Of note, an echocardiogram performed 11 months earlier had a normal EF of $55 \%$, mild LV hypertrophy, normal right ventricular performance and size, moderate aortic valve sclero-calcific changes with a mean systolic trans-aortic gradient of $20 \mathrm{mmHg}$, and a calculated aortic valve area by continuity equation of $1.2 \mathrm{~cm}^{2}$, consistent with moderate AS. No other valvular lesions were present at that time.

For further evaluation of possible underlying causes for the new onset of biventricular dysfunction, a cardiac magnetic resonance imaging with vasodilator stress and gadolinium contrast was performed. Late gadolinium enhancement was present in the basal and mid-ventricular septum in a pattern consistent with a dilated cardiomyopathy and not a myocardial infarction. No perfusion defects were noticed. Further workup revealed distal segmental right lower lobe pulmonary embolus and he was appropriately started on rivaroxaban for pulmonary embolus. Other medical therapy for decompensated heart failure included diuresis with intravenous furosemide, followed with transition to discharge medication including lisinopril $20 \mathrm{mg}$ daily, spironolactone $25 \mathrm{mg}$ daily, carvedilol XL $25 \mathrm{mg}$ daily, and furosemide $40 \mathrm{mg}$ daily. A 4-day course of prednisone $10 \mathrm{mg}$ was added in addition to home hydroxylchlorquine $200 \mathrm{mg}$ twice daily for his history of RA. Furthermore, certolizumab doses were held due to development of heart failure.

The patient's heart failure was medically optimized in followup consultations in our outpatient cardiology clinic, though he continued to demonstrate New York Heart Association Class III symptoms despite up-titration of goal-directed therapies of betablockers, angiotensin-converting enzyme inhibitors, aldosterone antagonists, and diuretics. It was postulated that his RA-related ILD, arterial hypertension, as well as suboptimal compliance with medications and diet were contributing to his ongoing dyspnea with minimal exertion.

Four months following his initial hospitalization and diagnosis of biventricular dysfunction and pulmonary embolism, the patient was re-hospitalized and admitted to the cardiac intensive care unit with respiratory distress requiring non-invasive positive pressure ventilation. Respiratory panel testing during workup revealed positive testing for Influenza $A$ virus. He was treated with oseltamivir and briefly required inotropic therapy in addition to continuous furosemide infusion. Repeat echocardiogram showed again severely reduced $\mathrm{EF}(<20 \%)$ now with qualitatively severe calcific changes of the aortic valve with a mean gradient of $17 \mathrm{mmHg}$ and an aortic valve area of $0.83 \mathrm{~cm}^{2}$. EKG showed sinus tachycardia at $123 \mathrm{bpm}$ but was otherwise unremarkable. Right and left heart catheterization was performed for further evaluation of cardiogenic shock. Coronary angiogram revealed no significant obstructive coronary artery disease. Invasive hemodynamic measurements during right and left heart catheterization demonstrated increased biventricular filling pressures (RA $12 \mathrm{mmHg}$, RV 52/12 mmHg, PA 50/30 with mean of $23 \mathrm{mmHg}$, and LVEDP $30 \mathrm{mmHg}$ ), mildly reduced cardiac output (PA saturation $73 \%$, cardiac index by Fick $2.9 \mathrm{~L} / \mathrm{min}$, and cardiac index by thermodilution $2.6 \mathrm{~L} / \mathrm{min}$ ), and moderate aortic stenosis with 
peak-to-peak pressure gradient of $20 \mathrm{mmHg}$ between left ventricle and ascending aorta, with a calculated aortic valve area of $1.5 \mathrm{~cm}^{2}$ by the Hakki equation (1). The patient subsequently recovered from cardiogenic shock exacerbated by influenza A virus and was discharged from the hospital on medical therapy with low doses of metoprolol, lisinopril, and furosemide. In addition, he was continued on anticoagulation for his previously diagnosed subsegmental pulmonary embolus and hydroxychloroquine for RA.

The next encounter was 3 weeks later in the outpatient cardiology clinic when the patient presented in compensated and stable chronic heart failure NYHA class III. He was in no distress, normotensive with some findings consistent with heart failure including elevated jugular vein distension $10 \mathrm{~cm}$ above the clavicle, fine inspiratory crackles bilaterally, and 1+ edema bilateral above the ankle. A dobutamine stress echocardiogram was performed to further characterize the severity of calcific aortic valve disease. With dobutamine $(20 \mu \mathrm{g} / \mathrm{kg} / \mathrm{min})$, the visual estimated EF increased from 25 to $43 \%$, and this was associated with a change of mean baseline aortic gradient of $12-19 \mathrm{mmHg}$, with a calculated aortic valve area by the continuity equation of $1.37 \mathrm{~cm}^{2}$. These findings are consistent with moderately severe aortic stenosis and moderate LV dysfunction with good contractile reserve. Given the patient's ongoing dyspnea and functional limitations, which had progressed over a year, along with new
LV dysfunction without alternate cause, referral for aortic valve replacement was made. His case was discussed in an interdisciplinary colloquium including general cardiology, rheumatology, pulmonology, interventional cardiology, and cardiothoracic surgery. CT-chest and pulmonary function testing were obtained for preoperative risk stratification. The results of the pulmonary function testing were as follows: TLC $3.81 \mathrm{~L}$ (=57\% of predicted), FVC $1.88 \mathrm{~L}$ (=42\% of predicted), FEV1 $1.55 \mathrm{~L}$ (=48\% of predicted), FEV1/FVC $82 \%$ (=114\% of predicted), and DLCO 8.78 ( $=32 \%$ of predicted) and were interpreted as moderately severe restrictive lung disease with a disproportionate reduction in diffusing capacity. The patient subsequently underwent surgical AVR with a 27-mm bioprosthetic aortic valve and tricuspid valve annuloplasty repair, and the initial post-op recovery was excellent. Patient's echocardiogram post aortic valve replacement revealed recovery of EF to 55\% (Table 2). However, on postoperative day 7 , he developed signs of decreased end-organ perfusion and was found to have pericardial tamponade for which he underwent a pericardial window procedure, which drained $360 \mathrm{~mL}$ blood from the pericardium. There were no other complications, and patient was discharged to subacute rehabilitation facility 12 days after cardiac surgery. He was seen 6 weeks later in the cardiology clinic and was found to be in atrial flutter with 2:1 conduction and a heart rate of $126 \mathrm{bpm}$. This was associated with only minimal

TABLE 2 | Diagnostic testing in evaluation of aortic stenosis.

\begin{tabular}{|c|c|c|c|}
\hline Test & Interpretation of the study & $\begin{array}{l}\text { Mean transaortic gradient } \\
(\mathrm{mmHg}) \text { and aortic valve } \\
\text { area }\left(\mathrm{cm}^{2}\right)\end{array}$ & $\begin{array}{l}\text { Ejection fraction } \\
(\%)\end{array}$ \\
\hline $\begin{array}{l}\text { 06/2013 } \\
\text { Echocardiography }\end{array}$ & $\begin{array}{l}\text { - Moderate sclerocalcific changes } \\
\text { - No AS, no Al }\end{array}$ & & 49 \\
\hline $\begin{array}{l}03 / 2014 \\
\text { Echocardiography }\end{array}$ & - Moderate sclerocalcific changes & $\begin{array}{l}\text { - } 11 \mathrm{mmHg} \\
\text { - } 1.6 \mathrm{~cm}^{2}\end{array}$ & 53 \\
\hline $\begin{array}{l}12 / 2014 \\
\text { Echocardiography }\end{array}$ & $\begin{array}{l}\text { - Moderate sclerocalcific changes } \\
\text { - Mild-moderate AS }\end{array}$ & $\begin{array}{l}\text { - } 19.5 \mathrm{mmHg} \\
\text { - } 1.2 \mathrm{~cm}^{2}\end{array}$ & 55 \\
\hline $\begin{array}{l}11 / 2015 \\
\text { Echocardiography } \\
\text { First presentation for new-onset heart } \\
\text { failure }\end{array}$ & $\begin{array}{l}\text { - Aortic stenosis, the severity of which cannot be accurately evaluated in } \\
\text { the presence of such profound left ventricular (LV) systolic dysfunction }\end{array}$ & & $10-15$ \\
\hline $\begin{array}{l}03 / 2016 \\
\text { Echocardiography } \\
\text { Presentation in cardiogenic shock, } \\
\text { influenza A virus }\end{array}$ & $\begin{array}{l}\text { - Technically difficult study } \\
\text { - LV moderately severe reduced } \\
\text { - Severe sclerocalcific changes }\end{array}$ & $\begin{array}{l}\text { - } 16.6 \mathrm{mmHg} \\
\text { - } 0.83 \mathrm{~cm}^{2}\end{array}$ & \\
\hline $\begin{array}{l}03 / 2016 \\
\text { LHC and RHC } \\
\text { Presentation in cardiogenic shock, } \\
\text { influenza A virus }\end{array}$ & $\begin{array}{l}\text { - Moderate AS } \\
\text { - Biventricular elevated filling pressures } \\
\text { - No obstructive CAD }\end{array}$ & $\begin{array}{l}\text { - LV/Aorta peak-to-peak } \\
\text { gradient: } 20 \mathrm{mmHg} \\
\text { - } 1.5 \mathrm{~cm}^{2}\end{array}$ & \\
\hline $\begin{array}{l}\text { 05/2016 } \\
\text { Dobutamine stress } \mathrm{ECHO}\end{array}$ & $\begin{array}{l}\text { - Good contractile reserve } \\
\text { - Fixed moderate AS } \\
\text { - Baseline global hypokinesis with augmentation of all segments with stress }\end{array}$ & $\begin{array}{l}\text { Gradient: } 12 \mathrm{mmHg} \text { and } \\
\text { increase to } 19 \mathrm{mmHg} \\
\text { Area: } 1.37 / 1.36 \mathrm{~cm}^{2}\end{array}$ & $\begin{array}{l}25 \text { and increase } \\
\text { to } 43\end{array}$ \\
\hline $\begin{array}{l}\text { 7/2016 } \\
\text { TEE-intraoperative during AVR }\end{array}$ & $\begin{array}{l}\text { - Severe aortic sclerosis with preserved leaflet opening. There is moderate } \\
\text { aortic stenosis. There is trace aortic regurgitation. }\end{array}$ & & \\
\hline $\begin{array}{l}7 / 2016 \\
\mathrm{ECHO}, \mathrm{POD} 4\end{array}$ & $\begin{array}{l}\text { - Bioprosthetic AVR } \\
\text { - Normal LV function }\end{array}$ & & $50-55$ \\
\hline
\end{tabular}

Patient had several echocardiograms performed between 2010 and 2016 due to his interstitial lung disease and chronic shortness of breath. 
symptoms of slightly increased dyspnea on excertion. He underwent DC cardioversion and has been doing very well since then with documented sinus rhythm 2 and 3 months later.

\section{DISCUSSION}

Aortic valve disorders are the most common valvular lesions requiring surgical intervention. Aortic valve replacement is commonly utilized for symptomatic patients with severe aortic stenosis. In the setting of aortic stenosis, maintenance of LV systolic function is achieved by a compensatory increase in LV wall thickness to balance the pressure overload from the obstructive valvular lesion. As the degree of valvular obstruction progresses, the compensatory mechanism of LV hypertrophy is overwhelmed by the underlying wall stress, and LV dilation and a fall in EF, along with the development of symptoms, occur (2). We speculate that in patients with underlying subclinical cardiomyopathies, compensatory mechanisms will be overwhelmed at even less than severe AS. However, the role of AVR in symptomatic patients with moderate AS is controversial, and selection of the best approach remains clinically challenging usually due to the presence of multiple confounding comorbidities (3). The role for AVR in documented low-flow, low-gradient aortic stenosis, classified as moderate in severity is not well defined (4). The current case is an example of aortic stenosis consistently characterized as "moderate AS" by echocardiography and invasive hemodynamics, but also with accelerated calcification of the aortic valve leaflets and rapid decline of LV function. We have stepwise documentation of rapidly declining LV systolic function from a normal EF to one of $15 \%$ within 1 year. The underlying mechanisms leading to the encountered severe LV dysfunction are likely multifactorial and possibly include increased afterload from moderate aortic stenosis, along with potential some cardiotoxic side effects of conventional and biologic disease modifying antirheumatic medications, although this is controversial $(5,6)$. Importantly, the profound LV dysfunction was completely reversed within days of valve replacement emphasizing the significant role of afterload reduction for the treatment of a failing left ventricle, which is commonly seen in patients with severe AS and LV dysfunction $(7,8)$.

Among patients with a failing left ventricle, relief of a fixed afterload reduction in the form of significant aortic stenosis may result in the greatest long-term survival benefit. The current American Heart Association valvular heart disease guidelines give a Grade IIb recommendation stating that it is reasonable to perform aortic valve replacement for moderate AS in patients who are undergoing other cardiac surgeries. There are no guideline recommendations to guide treatment of symptomatic patients with reduced LV systolic function and moderate AS. However, a contemporary study by Samad and colleagues sought to assess the effect of AVR with and without coronary artery bypass surgery and survival in patients with moderate and severe AS. Of the 1,634 patients included in this retrospective single-center analysis, 1,090 of those were classified as moderate by valve area of $>1 \mathrm{~cm}^{2}$ and mean gradient range of 25-39 mmHg. In a subgroup of those who underwent surgical AVR with a diagnosis of moderate AS, 135 underwent isolated AVR, while 152 had AVR plus coronary artery bypass surgery. In
135 patients who only had AVR, valve replacement within 90 days of index echocardiogram in the setting of moderate aortic stenosis and LV dysfunction (defined as $<50 \%, 108$ patients with $\mathrm{EF}<35 \%$ ) conferred a significant long-term mortality benefit of $42 \%$ compared to those who did not undergo surgery (9). Although this was not a randomized clinical trial, the data suggest that AVR for moderate AS with LV dysfunction resulted in superior outcome over medical therapy in selected patients. Prior detriments to referring patients with symptomatic AS for valve replacement may include advanced age with short life expectancy, LV dysfunction, lung disease, and renal disease $(10,11)$. These data suggest that in the setting of LV dysfunction with moderate AS, as a contributor or bystander condition, relief of the hemodynamic burden of additional afterload likely contributes a significant survival benefit in selected patients. In the last decade, transcatheter aortic valve replacement (TAVR) has become the preferred treatment option for patients with severe AS and high operative risk (12). Recent trial data have even suggested that TAVR is non-inferior to surgical AVR in patients in intermediate-risk severe AS (13). Coexisting moderate AS and LV systolic dysfunction is not uncommon, and now with the advent of TAVR, upcoming clinical trials will seek to address whether a less invasive approach such as TAVR may be a viable strategy to reduce afterload in patient's with LV systolic dysfunction and concomitant moderate aortic stenosis, who are of high surgical risk (14).

Our patient did not have baseline chronic kidney disease, diabetes, abnormalities in calcium and phosphorus serum concentrations, or advanced age, which are all common risk factors associated with calcific aortic valve disease. The underlying pathophysiology of accelerated calcification in patients with RA is poorly understood with a paucity of literature or guidelines to guide management. Although data on valvular disease are scarce, there is published literature on increased rates of coronary artery calcification in this population, which may represent a shared etiology (15-18). Whether this is related to autoimmune disease severity over time or is increased in all patients with RA is a matter of continuing investigation. However, it is plausible that vascular inflammation may contribute to both valvular and coronary artery changes by the same common mechanisms. Research now implicates osteogenic processes as key mechanism in calcific aortic valve disease and thereby providing two general directions for development of new therapies (1): inhibition of procalcific regulators and (2) induction of proresorptive regulators in aortic valve tissue $(19,20)$. However, tissue targeting may be essential to avoid damage to skeletal bone for example.

Calcific aortic valve disease commonly occurs in patients with bicuspid aortic valves (BAV). These patients present for AVR at a younger age and often have no concommittant obstructive coronary artery disease. It is estimated that up to $50 \%$ of patients requiring surgical AVR for severe aortic stenosis have BAV. Hemodynamic and developmental abnormalities of the congenital bicuspid aortic valve may predispose to premature calcification and valve failure, although no specific mechanisms have been reported. In contrast, patients with trileaflet aortic valve with severe calcification and stenosis present later in life for AVR (one decade later compared to BAV) and commonly share atherosclerotic risk factors, such as diabetes, chronic kidney disease, and increased 
levels of oxidized LDL. Up to $60 \%$ of patients with trileaflet AV and severe stenosis require coronary artery bypass grafting for obstructive coronary artery disease, which is only required in up to $10 \%$ in patients with BAV and severe stenosis (21). However, cellular mechanisms leading to calcific aortic valve disease remain incompletely understood, and as demonstrated in this case, our patient has a trileaflet aortic valve, no coronary artery disease, and no other atherosclerotic risk factors beyond RA.

\section{CONCLUDING REMARKS}

Taken together, the current guidelines do not support routine AVR in moderate AS not undergoing concomitant cardiac surgery. Severe calcification alone in mild and moderate aortic stenosis independently predicts the rate of disease progression and survival in these populations (20). Careful evaluation for other causes of LV dysfunction and symptoms should be undertaken in patients who do not meet standard criteria for AVR. In these patients with progressive symptoms and no other clear explanation, the correction of a hemodynamic burden such as a calcified

\section{REFERENCES}

1. Hakki AH, Iskandrian AS, Bemis CE, Kimbiris D, Mintz GS, Segal BL, et al. A simplified valve formula for the calculation of stenotic cardiac valve areas. Circulation (1981) 63(5):1050-5. doi:10.1161/01.CIR.63.5.1050

2. Murphy JG. Mayo Clinic Cardiology: Concise Textbook. Oxford, England: Oxford University Press (2012).

3. Otto CM, Prendergast B. Aortic-valve stenosis - from patients at risk to severe valve obstruction. N Engl J Med (2014) 371(8):744-56. doi:10.1056/ NEJMra1313875

4. Nishimura RA, Otto CM, Bonow RO, Carabello BA, Erwin JP III, Guyton RA, et al. 2014 AHA/ACC guideline for the management of patients with valvular heart disease: a report of the American College of Cardiology/American Heart Association Task Force on Practice Guidelines. J Am Coll Cardiol (2014) 63(22):e57-185. doi:10.1016/j.jacc.2014.02.536

5. Joyce E, Fabre A, Mahon N. Hydroxychloroquine cardiotoxicity presenting as a rapidly evolving biventricular cardiomyopathy: key diagnostic features and literature review. Eur Heart J Acute Cardiovasc Care (2013) 2(1):77-83. doi:10.1177/2048872612471215

6. Cush JJ. Unusual toxicities with TNF inhibition: heart failure and drug-induced lupus. Clin Exp Rheumatol (2004) 22(5 Suppl 35):S141-7.

7. Connolly HM, Oh JK, Orszulak TA, Osborn SL, Roger VL, Hodge DO, et al. Aortic valve replacement for aortic stenosis with severe left ventricular dysfunction. Prognostic indicators. Circulation (1997) 95(10):2395-400. doi:10.1161/01.CIR.95.10.2395

8. Dauerman HL, Reardon MJ, Popma JJ, Little SH, Cavalcante JL, Adams DH, et al. Early recovery of left ventricular systolic function after core valve transcatheter aortic valve replacement. Circ Cardiovasc Interv (2016) 9(6):1-10. doi:10.1161/CIRCINTERVENTIONS.115.003425

9. Samad Z, Vora AN, Dunning A, Schulte PJ, Shaw LK, Al-Enezi F, et al. Aortic valve surgery and survival in patients with moderate or severe aortic stenosis and left ventricular dysfunction. Eur Heart J (2016) 37(28):2276-86. doi:10.1093/eurheartj/ehv701

10. Iung B, Baron G, Butchart EG, Delahaye F, Gohlke-Barwolf C, Levang OW, et al. A prospective survey of patients with valvular heart disease in Europe: the Euro Heart Survey on valvular heart disease. Eur Heart J (2003) 24(13):1231-43. doi:10.1016/S0195-668X(03)00201-X

11. Iung B, Cachier A, Baron G, Messika-Zeitoun D, Delahaye F, Tornos P, et al. Decision-making in elderly patients with severe aortic stenosis: why are so many denied surgery? Eur Heart J (2005) 26(24):2714-20. doi:10.1093/ eurhearti/ehi471

12. Rodes-Cabau J, Webb JG, Cheung A, Ye J, Dumont E, Feindel CM, et al. Transcatheter aortic valve implantation for the treatment of severe symptomatic aortic stenosis in patients at very high or prohibitive surgical risk: acute valve, even if only moderately severe when measured by mean aortic valve gradient, should be considered.

\section{ETHICS STATEMENT}

This research was approved by the University of Chicago Institutional Review Board. Further written consent for publication of this case report was obtained from the patient.

\section{AUTHOR CONTRIBUTIONS}

All authors contributed to the analysis and interpretation of data, wrote the manuscript, approved the final version of the manuscript, and agreed to be accountable for all aspects of the work.

\section{FUNDING}

This study is supported by the National Health Lung and Blood Institute (1R011HL4821 to $\mathrm{MB}$ on research on calcific aortic valve disease).

and late outcomes of the multicenter Canadian experience. J Am Coll Cardiol (2010) 55(11):1080-90. doi:10.1016/j.jacc.2009.12.014

13. Leon MB, Smith CR. Transcatheter aortic-valve replacement. N Engl J Med (2016) 375(7):700-1. doi:10.1056/NEJMc1606814

14. Spitzer E, Van Mieghem NM, Pibarot P, Hahn RT, Kodali S, Maurer MS, et al. Rationale and design of the transcatheter aortic valve replacement to unload the left ventricle in patients with advanced heart failure (TAVR UNLOAD) trial. Am Heart J (2016) 182:80-8. doi:10.1016/j.ahj.2016.08.009

15. Chung CP, Oeser A, Raggi P, Gebretsadik T, Shintani AK, Sokka T, et al. Increased coronary-artery atherosclerosis in rheumatoid arthritis: relationship to disease duration and cardiovascular risk factors. Arthritis Rheum (2005) 52(10):3045-53. doi:10.1002/art.21288

16. Giles JT, Szklo M, Post W, Petri M, Blumenthal RS, Lam G, et al. Coronary arterial calcification in rheumatoid arthritis: comparison with the Multi-Ethnic Study of Atherosclerosis. Arthritis Res Ther (2009) 11(2):R36. doi:10.1186/ar2641

17. Wang S, Yiu KH, Mok MY, Ooi GC, Khong PL, Mak KF, et al. Prevalence and extent of calcification over aorta, coronary and carotid arteries in patients with rheumatoid arthritis. J Intern Med (2009) 266(5):445-52. doi:10.1111/j.1365-2796.2009.02123.x

18. Kao AH, Krishnaswami S, Cunningham A, Edmundowicz D, Morel PA, Kuller $\mathrm{LH}$, et al. Subclinical coronary artery calcification and relationship to disease duration in women with rheumatoid arthritis. J Rheumatol (2008) 35(1):61-9.

19. Yutzey K, Demer L, Body SC, Huggins GS, Towler DA, Giacelli CM, et al. Calcific aortic valve disease: a consensus summary from the alliance of investigators on calcific aortic valve disease. Arterioscler Thromb Vasc Biol (2014) 34:2387-93. doi:10.1161/ATVBAHA.114.302523

20. Rosenhek R, Klaar U, Schemper M, Scholten C, Heger M, Gabriel H, et al. Mild and moderate aortic stenosis. Natural history and risk stratification by echocardiography. Eur Heart J (2004) 25(3):199-205. doi:10.1016/j. ehj.2003.12.002

21. Roberts WC. The congenitally bicuspid aortic valve. A study of 85 autopsy cases. Am J Cardiol (1970) 26(1):72-83. doi:10.1016/0002-9149(70)90761-7

Conflict of Interest Statement: The authors declare that the research was conducted in the absence of any commercial or financial relationships that could be construed as a potential conflict of interest.

Copyright (c) 2017 Narang, Lang, Liarski, Jeevanandam and Hofmann Bowman. This is an open-access article distributed under the terms of the Creative Commons Attribution License (CC BY). The use, distribution or reproduction in other forums is permitted, provided the original author(s) or licensor are credited and that the original publication in this journal is cited, in accordance with accepted academic practice. No use, distribution or reproduction is permitted which does not comply with these terms. 